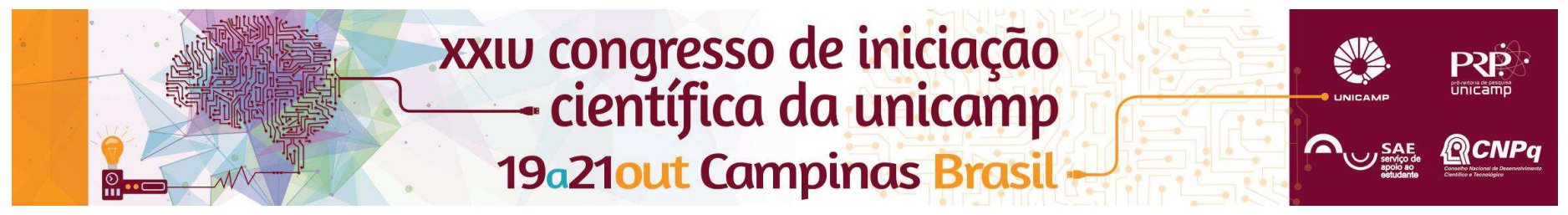

\title{
Projeto e construção de um amplificador em estado sólido na banda de UHF
}

\author{
Felipe S. P. Oliveira*, Lucas H. Gabrielli.
}

\section{Resumo}

Dadas as necessidades advindas com a demanda de novos sistemas de RF a serem montados para o acelerador de partículas brasileiro em construção, Sirius, e o conhecimento adquirido pelo estudo de um módulo amplificador de 476 $\mathrm{MHz}$ realizado no segundo semestre de 2015 [1], se fez pertinente a execução do projeto e construção de um amplificador em estado sólido para operação em $500 \mathrm{MHz}$. Neste sentido, este projeto envolveu a definição dos parâmetros de performance deste amplificador, escolha do transistor, design das redes de polarização e casamento via ferramentas de simulação, testes de varredura e sensibilidade, desenho da placa de circuito impresso (PCB) do primeiro protótipo e medidas comparativas entre protótipo real e resultados de simulações.

\section{Palavras-chave}

Amplificador RF, casamento de impedância, simulação RF.

\section{Introdução}

O grupo de radiofrequência do Laboratório Nacional de Luz Síncrotron (LNLS), localizado em Campinas-SP possui em seu escopo de trabalho o desenvolvimento, especificação, montagem e suporte de amplificadores de RF para aplicações em alta potência (de dezenas de kW à dezenas de $\mathrm{MW}$ ).

Assim, tal grupo encontra-se engajado aos projetos para - Sirius, sendo uma de suas responsabilidades a especificação de amplificadores em estado sólido voltados para a injeção de energia em cavidades ressonantes de RF.

Baseados em [1] e nos conhecimentos pertinentes a caracterização de amplificadores de RF [2], executamos no primeiro semestre de 2016 o projeto e construção de um amplificador de RF para operação em $500 \mathrm{MHz}$.

\section{Resultados e Discussão}

Dividimos este trabalho em duas etapas: simulação e prototipagem.

Para a simulação do projeto levantamos os componentes principais de nosso amplificador e circuitos base já existentes (amplificador de $476 \mathrm{MHz}$ do LNLS e outros modelos fornecidos pelo fabricante do transistor de RF). Posteriormente, fizemos uso da ferramenta de simulação levando em consideração modelos circuitais tanto com componentes distribuídos como concentrados para desenvolvimento do nosso primeiro circuito, desenvolvendo inicialmente os blocos básicos de um amplificador de RF, à saber, redes de polarização e casamento de entrada e saída e, a seguir, verificando o desempenho do circuito completo até que o mesmo tivesse a performance da figura 1.

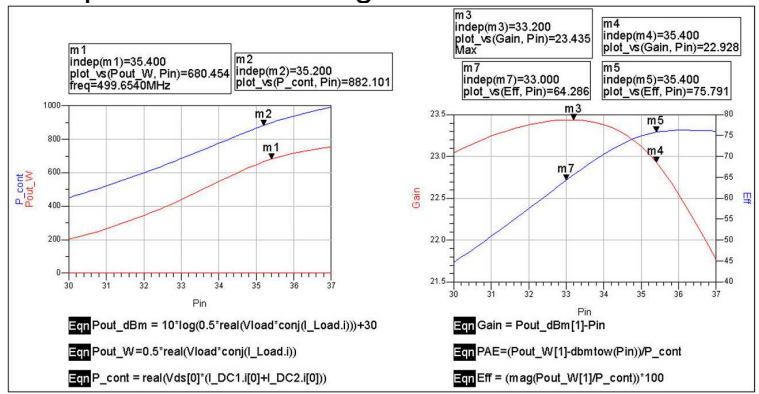

Figura 1. Desempenho de potência de saída, ganho e eficiência do amplificador projetado.

Já a nível de hardware, utilizamos um CAD específico para o desenho do circuito em PCB segundo o projeto obtido na etapa anterior, executamos a fabricação da PCB e montagem do circuito no LNLS, realizando neste amplificador testes preliminares das redes de casamento de entrada e saída e redes de polarização dos drenos e gates, alimentando-os com $48 \mathrm{~V}$ e $1,88 \mathrm{~V}$, respectivamente. $\mathrm{Na}$ figura 2 têm-se a versão final do primeiro protótipo sem o transistor de RF.

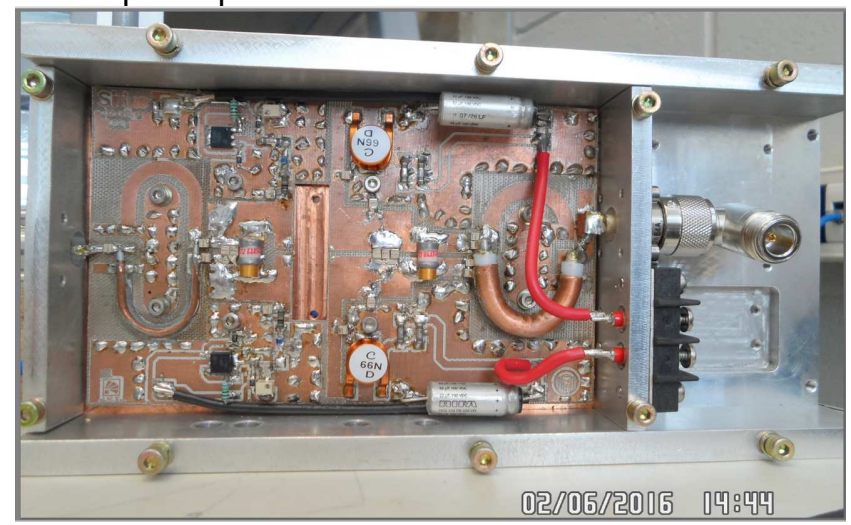

Figura 2. Protótipo versão 1 segundo 0 projeto com desempenho da figura 1.

\section{Conclusões}

Ressalta-se neste trabalho o emprego efetivo do estudo teórico empregado em [1] e a expectativa real de se obter um amplificador de RF com potência de saída nominal de $700 \mathrm{~W}$, ganho de $23 \mathrm{~dB}$ e eficiência de $75 \%$ à esta potência. No segundo semestre de 2016 serão realizados todos os testes pertinentes a este circuito e desenvolvimento de novos protótipos até a consolidação do amplificador de RF desenvolvido pelo LNLS.

\section{Agradecimentos}

Ao meu orientador Lucas $H$. Gabrielli e a todo o grupo RFQ do LNLS pelo trabalho conjunto.

${ }^{1}$ F. S. de Oliveira; L. H. Gabrielli, "Estudo de módulo amplificador em estado sólido para UHF," Relatório de IC (EE015), FEEC, Unicamp, Junho 2015.

2 D. M. Pozar, Microwave Engineering, New York, Wiley, $4^{\text {th }}$ edition, Nov. 2000 . 